\title{
Post-radiation airway management - An anesthesiologist's challenge
}

\author{
Bhavna Sriramka, Daisy Karan, Madhu Parida \\ Department of Anesthesia and Critical Care, IMS \& Sum Hospital, Bhubaneswar, Odisha, India
}

Keywords: Difficult Airway; Laryngeal Edema; Radiation.

This is an Open Access article distributed under the terms of the Creative Commons Attribution Non-Commercial License (http://creativecommons.org/licenses/by-nc/4.0/) which permits unrestricted non-commercial use, distribution, and reproduction in any medium, provided the original work is properly cited.

Sir,

Malignancies affecting the head and neck regions pose a challenge to the anesthesiologist owing to alterations in the local anatomy that may arise because of the mass effect, sometimes post-surgery during a re-exploration or second surgery, or due to radiation treatment [1]. The anesthesiologist is confronted with the task of securing the airway and allowing the surgeons to work, often in the same field. The difficulty may vary among individuals and patient-wise. We discuss a tricky scenario that we encountered recently.

A 32-year-old man with a BMI of $28 \mathrm{~kg} / \mathrm{m}^{2}$ was scheduled to undergo left radical neck dissection. He was diagnosed with carcinoma tongue, for which he underwent a right-sided hemi-glossectomy along with ipsilateral, modified, radical neck dissection about eight months prior. Subsequently, he received radiotherapy (33 fractions of radiation therapy), the last session being four months prior. The patient visited the onco-surgeon for follow up with a left-sided neck swelling and mild breathing difficulty. Neck computed tomography revealed that the left cervical nodes had metastatic infiltration. His pre-anesthetic work up included routine laboratory investi- gations, the results of which were within normal limits, and a radiograph of the chest and neck. The neck radiograph showed severe narrowing of the airway at the level of the glottis (Fig. 1 and 2). Restricted mouth opening (two-finger opening) and no restriction of neck movements were observed. General anesthesia with awake flexible fiber-optic intubation was planned for the surgery.

Patient was given Inj. glycopyrrolate $0.2 \mathrm{mg}$ followed by Inj. midazolam $1 \mathrm{mg}$ intravenously. After nebulizing the patient with $4 \%$ lignocaine, the "spray as you go technique" was chosen for airway anesthesia because altered anatomy was suspected. Then, $3 \mathrm{~mL}$ of intratracheal Inj. 4\% lignocaine was administered. A cuffed flexo-metallic endotracheal tube (ETT) of $6.5-\mathrm{mm}$ internal diameter (ID) was loaded over the fiberoptic bronchoscope, and the bronchoscope was inserted into the oral cavity. It was easily negotiated into the oral cavity up to the level of layngo-pharynx, where uneven tissue edema extending into the glottic and subglottic areas was observed. The supraglottic, glottis, and subglottic areas were found to be narrowed, even though the tracheal rings were normal. Even though the passage of the broncho-

Received: January 20, 2019 - Revised: February 4, 2019 - Accepted: February 4, 2019

Corresponding Author: Bhavna Sriramka, Department of Anesthesia and Critical Care, IMS \& Sum Hospital, 106 Mahadev Orchid, Cosmopolis road Dumduma, Bhubaneswar, Odisha 751019, India

Tel: +917751007807 E mail: bhavna.sriramaka@gmail.com

Copyright@ 2019 Journal of Dental Anesthesia and Pain Medicine 


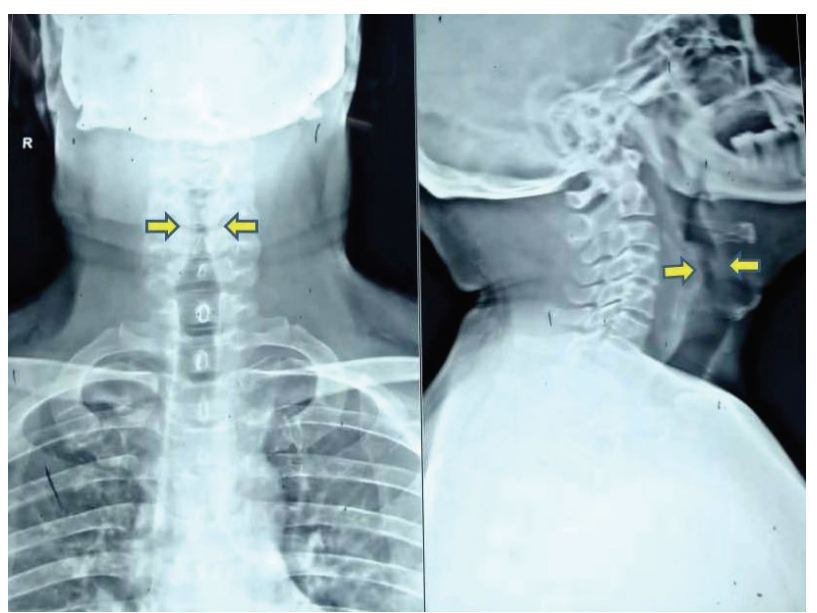

Fig. 1. Anteroposterior and lateral $x$-ray of the neck showing a narrowing in the airway (arrow marked).

scope was smooth, we decided to use a smaller-diameter ETT (5.5-mm ID uncuffed) due to the presence of laryngeal constriction. Our aim was to avoid any injury to the edematous airway. Surgeon was alarmed for an emergency tracheostomy for a possible chance of failure to secure the airway. The bronchoscope was removed, and we reloaded with a 5.5-mm ETT. The whole procedure was repeated and we secured the airway with this tube that remained snugly fit. During removal of the bronchoscope, the airway was examined through the ETT for any possible injury. However, no such injury was observed. General anesthesia was administered, and the surgery was uneventful. At the end of the procedure, the patient was extubated and observed for 30 minutes before being shifted to the intensive care unit for monitoring.

Lymphatic drainage is impaired by the previous surgery. This scenario with superadded radiation can also induce edema with consequent fibrosis; there may even be necrosis depending on the dosage and duration of radiation [1]. The changes may occur in all areas in the field of exposure, and the challenge for the anesthesiologist remains in every step of airway management [2]. Hence, a proper assessment and pre-operative evaluation are mandatory in such patients. A simple method including three steps of clinical tests, the atlanto-occipital extension, mandibular space, and the tongue versus pharyngeal size, must be followed by examination by

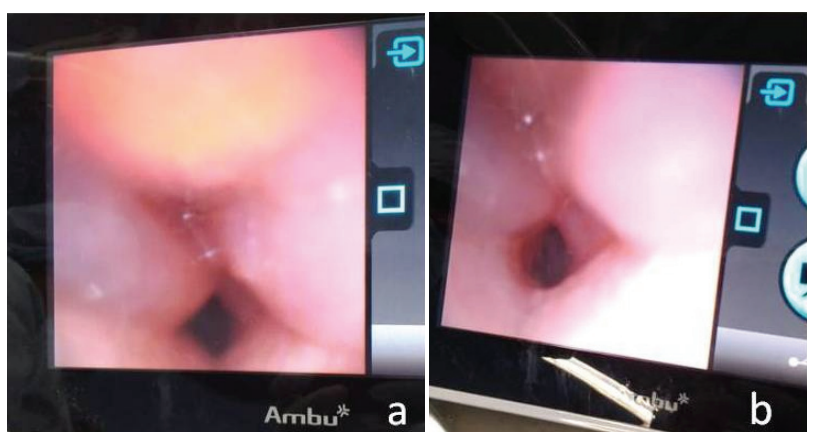

Fig. 2. Picture from fibreoptic view showing narrowing and edema in the glottic (a) and subglottic areas (b).

indirect laryngoscopy prior to the procedure $[3,4]$. Radiological evaluation can also provide an insight into possible constriction of the airway, as in our case [5]. The procedure must be performed gently with supervision through a fiberoptic bronchoscope to prevent any further injury to the friable tissue. The size of the ETT may be surprisingly smaller than anticipated. Lastly, there should be no hesitation in performing a tracheostomy, should there be an impending danger of a compromised airway [1].

\section{AUWHOR ORGIDS}

Bhavna Sriramka: https://orcid.org/0000-0001-8439-5908

Daisy karan: https://orcid.org/0000-0001-7649-7541

Madhusmita Parida: https://orcid.org/0000-0001-9991-976X

\section{REFERENCES}

1. Balakrishnan M, Kuriakose R, Koshy RC. Radiation induced changes in the airway-anaesthetic implications. South African J Anaesth Analg 2004; 10: 19-21.

2. Egan TD, Wong KC. Predicting difficult laryngoscopy for tracheal intubation: an approach to airway assessment. Ma Zui Xue Za Zhi 1993; 31: 165-78.

3. Biebuyck JF, Benumof JL. Management of the Difficult Adult Airway With Special Emphasis on Awake Tracheal Intubation. Anesthesiology 1991; 75: 1087-110.

4. Kuriakose R, Mathew A, Koshy R. Screening tests for predicting difficult endotracheal intubation. A clinical 
assessment in facio-oromaxillary and neck malignancy patients. J Anaesth Clin Pharmacol 2003; 19:37-44.

5. Huitink JM, Balm AJM, Keijzer C, Buitelaar DR. Awake fibrecapnic intubation in head and neck cancer patients with difficult airways: New findings and refinements to the technique. Anaesthesia 2007; 62: 214-9. 